\title{
Performance Evaluation of Solar PV Inverter Controls for Overvoltage Mitigation in MV Distribution Networks
}

\author{
Dilini Almeida ${ }^{1, *}$, Jagadeesh Pasupuleti ${ }^{1}$, Shangari K. Raveendran ${ }^{1}$ and M. Reyasudin Basir Khan ${ }^{2}$ D \\ 1 College of Engineering, Universiti Tenaga Nasional (UNITEN), Putrajaya 43000, Malaysia; \\ jagadeesh@uniten.edu.my (J.P.); shangari@uniten.edu.my (S.K.R.) \\ 2 School of Science and Engineering, Manipal International University, Nilai 71800, Malaysia; \\ mohammed.reyasudin@miu.edu.my \\ * Correspondence: dilinialmeida2@gmail.com
}

check for

updates

Citation: Almeida, D.; Pasupuleti, J.; Raveendran, S.K.; Basir Khan, M.R. Performance Evaluation of Solar PV Inverter Controls for Overvoltage Mitigation in MV Distribution Networks. Electronics 2021, 10, 1456. https://doi.org/10.3390/ electronics10121456

Academic Editors: Nicu Bizon, Yuchen Zhang and Z.Y. Dong

Received: 10 May 2021

Accepted: 8 June 2021

Published: 18 June 2021

Publisher's Note: MDPI stays neutral with regard to jurisdictional claims in published maps and institutional affiliations.

Copyright: (c) 2021 by the authors. Licensee MDPI, Basel, Switzerland. This article is an open access article distributed under the terms and conditions of the Creative Commons Attribution (CC BY) license (https:/ / creativecommons.org/licenses/by/ $4.0 /)$.

\begin{abstract}
The incorporation of real and reactive power control of solar photovoltaic (PV) inverters has received significant interest as an onsite countermeasure to the voltage rise problem. This paper presents a comprehensive analysis of the involvement of active power curtailment and reactive power absorption techniques of solar PV inverters for voltage regulation in medium voltage (MV) distribution networks. A case study has been conducted for a generic MV distribution network in Malaysia, demonstrating the effectiveness of fixed power factor control, Volt-Var, and Volt-Watt controls in mitigating overvoltage issues that have arisen due to the extensive integration of solar PV systems. The results revealed that the incorporation of real and reactive power controls of solar PV inverters aids in successfully mitigating overvoltage issues and support network operating conditions. Furthermore, the comparative analysis demonstrated the importance of employing the most appropriate control technique for improved network performance.
\end{abstract}

Keywords: MV distribution network; PV penetration; voltage rise; active power curtailment; reactive power absorption

\section{Introduction}

In recent years, Distributed Energy Resources (DERs), such as solar photovoltaic (PV) systems, have made inroads into distribution networks, gaining a significant share of the generation mix. However, the increasing levels and intermittent nature of solar PV systems impose a variety of implications in conventional PV-rich distribution networks, where voltage regulation has become a difficult task due to the presence of distributed supply points [1,2]. The overvoltage issues attributed to reverse power flow have been recognized as the key limiting factor for solar PV integration in distribution networks [3,4]. The undesirable voltage levels at the connection points could significantly exceed the voltage limits, resulting in frequent disconnections of PV inverters and deterioration of network reliability [5]. In order to maintain grid voltage levels within the specified boundaries, the Distribution Network Operators (DNOs) that guarantee the power quality of the distribution network are required to enforce restrictions on the integration of new PV systems into the distribution grid, and also to undertake network reinforcement, which would eventually lead to massive capital investments. Therefore, it is of vital importance to propose effective mitigation strategies, focusing on a smooth operation and optimal PV penetration.

Previously, the power intermittency of PV systems resulted in frequency deviations in distribution grids, deteriorating the frequency stability of the power system owing to the incapability of supplying inertia. As a result, the absence of rotational inertia emerged as the primary barrier to integrating PV systems into the distribution grid using power electronic converters. However, in recent years, the transition from passive to active distribution networks has arisen as an enticing alternative solution, where controllable 
devices and low carbon technologies are actively managed to provide grid-supportive services [6].

The increased solar PV penetration and consequent challenges have accelerated the incorporation of solar PV inverters with smart/advanced functionalities to alleviate the potential impacts due to high solar PV penetration. Unlike the conventional solar PV inverters, the modern solar PV inverters are deemed to be intelligent, as they can provide advanced functionalities instead of merely converting the direct current output of solar panels into an alternating current. These advanced functionalities allow solar PV inverters to monitor and communicate the status of the system and then to make autonomous decisions to provide ancillary services to the network [7]. Voltage and frequency regulation are two of the most popular ancillary services provided by smart PV inverters that help the system to maintain the voltage and frequency levels within the permissible limits and standards. It has been identified that the adoption of these smart PV inverters could minimize the integration of voltage and frequency control devices into the distribution grid, thus reducing the installation and maintenance costs.

A considerable number of research efforts have been carried out in the literature to assess the contribution of PV systems for providing grid support and ancillary services [8,9]. Among different voltage controls provided by solar PV inverters, active power curtailment (APC) and reactive power absorption (RPA) have been established as viable solutions for overvoltage problems associated with extensive solar PV integration in distribution networks [10]. In the event of voltage violations due to high solar PV influx, the APC could be adopted to confine the maximum active power output of solar PV inverters and thereby regulate the grid voltage within the permissible voltage limits. The authors of [11-13] have proposed APC techniques to resolve overvoltage problems associated with high solar $\mathrm{PV}$ penetration in LV distribution networks. Despite being an effective countermeasure for overvoltage problems, APC is not a favorable option for PV owners due to revenue loss. However, this approach is still useful in circumstances where the prevailing voltage controllers are incapable of avoiding voltage violations in the network. As per the literature review, many researchers have studied different RPA techniques of solar PV inverters to manage overvoltage issues in LV distribution networks [14-18]. Among these, the fixed power factor control, power factor control as a function of injected active power $(\cos \phi(\mathrm{P}))$, and voltage-dependent reactive power provision $(\mathrm{Q}(\mathrm{V}))$ are the key reactive power support solutions proposed by past researchers. At present, the Volt-Var and Volt-Watt controls of smart PV inverters have gained attention in facilitating localized voltage control. Owing to the simple design and ease of implementation, these controls have been adopted by the IEEE 1547 standard [19] and several on-board initiatives, such as California's Rule 21 [20] and Hawaii's rule $14 \mathrm{H}$ [21].

In most of the foregoing literature, the researchers have only focused on overvoltage mitigation in LV distribution networks. Nevertheless, a few studies have been explored to alleviate voltage violations in medium voltage (MV) distribution networks. Reference [22] has assessed the adoption of inverter controllers in resolving voltage rise issues in a typical Hungarian MV distribution network. The authors of [23] have investigated the performance of the sequential RPA-APC control function in mitigating overvoltage problems that arise from the integration of large-scale PV systems into an MV distribution network in the Netherlands. The effectiveness of local Volt-Var control of solar PV systems for overvoltage mitigation has been assessed by the authors of [24], using a modified IEEE 33 bus system. For [25], a comparative analysis was conducted to analyze different RPA strategies in active MV networks. However, due to the particular fundamental architecture of the power system, most of the test networks involved in the above studies are not pragmatic for countries such as Malaysia. Moreover, the previous studies have not conducted a detailed comparison among different types of solar PV inverter controllers in alleviating overvoltage issues in MV distribution networks.

While the revised IEEE 1547 standard has allowed PV inverters to actively participate to regulate the grid voltage, it is not yet been stipulated under the current guidelines of 
the Malaysian grid code. Nonetheless, due to the rising number of PV installations in the Malaysian distribution network, new voltage management approaches are required to be adopted to mitigate the overvoltage issues. As per the knowledge of the authors, these mitigation techniques have not been evaluated for Malaysian networks.

In this context, this paper evaluates the involvement of several APC and RPA techniques of solar PV inverters, namely fixed power factor, Volt-Var, and Volt-Watt controls, in mitigating overvoltage problems due to high PV penetration in Malaysian MV distribution networks. The effectiveness of the studied controllers was examined and quantified on a generic Malaysian MV network concerning a range of performance metrics, including the number of nodes with voltage infringements, active power curtailment, reactive power absorption, and network losses.

The remainder of the paper is organized as follows. Section 2 provides an overview of the research method, including the APC and RPA functionalities of solar PV inverters, and the methodology adopted to evaluate the performance of real and reactive power control techniques of solar PV inverters for overvoltage mitigation in MV distribution networks. The case study and the simulation results are illustrated in Sections 3 and 4, respectively. Finally, the results are discussed in Section 5 , and the conclusions of the study are drawn in Section 6.

\section{Research Method}

This section presents the research method adopted to evaluate the performance of different real and reactive power control techniques of solar PV inverters for overvoltage mitigation in MV distribution networks.

\subsection{Voltage Control Functionalities of Solar PV Inverters}

The control of active and reactive power output for localized voltage regulation could be recognized as the most prominent functionality of modern solar PV inverters. The following sections discuss the APC and RPA techniques of solar PV inverters utilized in this study.

\subsubsection{Active Power Curtailment of Solar PV Inverters}

In this study, the droop-based APC of solar PV inverters (Volt-Watt control) was assessed for mitigating overvoltage issues due to the increased solar PV penetration in MV distribution networks. In the Volt-Watt control mode, PV inverters are allowed to monitor terminal voltage and curtail active power output based on the Point of Common Coupling (PCC) voltage, and the Volt-Watt setpoints defined by the utility. The relationship between the active power output and the voltage is usually defined by a piecewise linear curve, as illustrated in Figure 1.

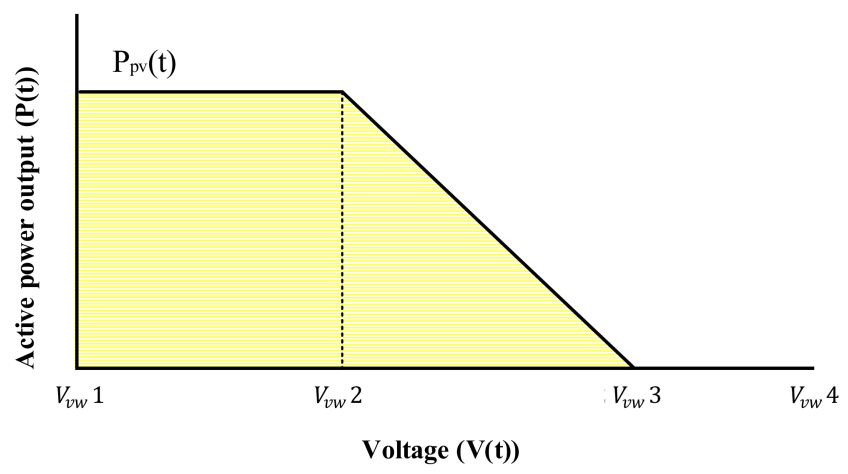

Figure 1. Volt-Watt curve characteristics.

As depicted in the figure, no active power reduction is triggered up to a predetermined lower voltage bound $\left(V_{v w} 2\right)$ and the maximum available active power generation is injected into the grid. When the voltage exceeds the lower bound and varies between $V_{v w} 2$ and 
$V_{v w} 3$, the active power output is curtailed in accordance with the slope of the curve. Once the voltage reaches the upper voltage bound $\left(V_{v w} 3\right)$, the active power output is completely curtailed to maintain the voltage within the permissible voltage limits. The computed active power output could be mathematically expressed as in Equation (1).

$$
P(t)=\left\{\begin{array}{cl}
P_{p v}(t) & ; \text { if } V(t) \leq V_{v w} 2 \\
\frac{V_{v w} 3-V(t)}{V_{v w} 3-V_{v v w 2} 2} P_{p v}(t) & ; \text { if } V_{v w} 2<V(t) \leq V_{v w} 3 \\
0 & ; \text { if } V(t)>V_{v w} 3
\end{array}\right.
$$

where $P(t)$ is the computed active power output by Volt-Watt control.

\subsubsection{Reactive Power Absorption of Solar PV Inverters}

The RPA of solar PV inverters is one of the most widely adopted overvoltage mitigation techniques in distribution networks. In this approach, the voltage regulation is accomplished by the absorption of reactive power by solar PV inverters. The reactive power compensation depends on the reactive power capability of the PV inverter $Q_{\max }$, which is defined as Equation (2).

$$
Q_{\max }(t)=\sqrt{S_{i n v}^{2}-P_{p v}^{2}(t)}
$$

where $S_{i n v}$ and $P_{p v}$ are the apparent power rating and the active power output of the PV inverter, respectively.

In this study, two RPA techniques of solar PV inverters, namely the fixed power factor control and the Volt-Var control, were assessed for preventing overvoltage issues due to the increased solar PV penetration in MV distribution networks.

In fixed power factor control, the solar PV inverters are adjusted to operate at constant leading power factors, where the RPA is proportional to the active power generation. The representation of the fixed power factor control is shown in Figure 2.

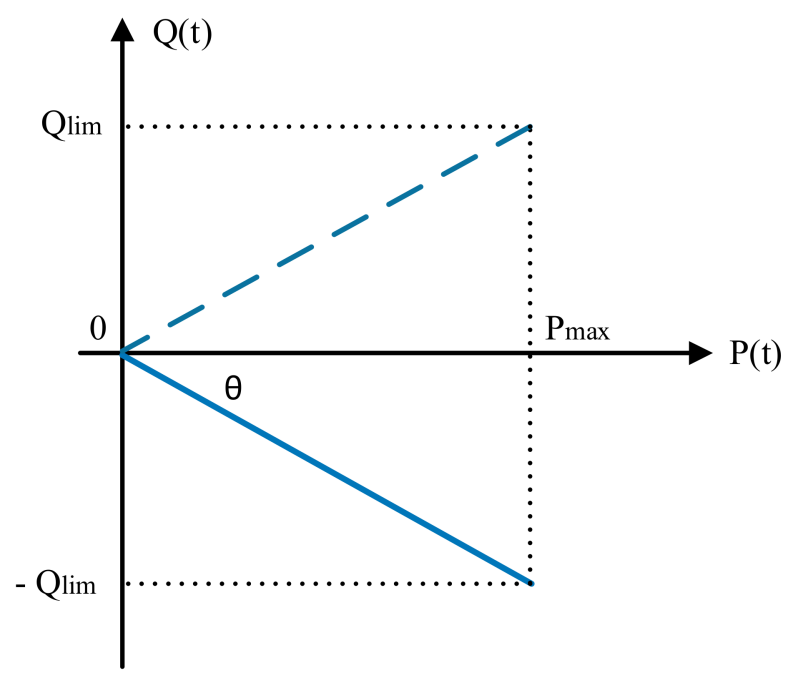

Figure 2. Fixed power factor control.

As can be seen, the RPA is lower during low active power generation, whilst the maximum possible reactive power $\left(Q_{\text {lim }}\right)$ is absorbed when the maximum active power generation $\left(P_{\max }\right)$ arises.

In the Volt-Var control mode, PV inverters are allowed to monitor terminal voltage and deliver a custom reactive power response based on the PCC voltage, the available reactive power capability, and the Volt-Var setpoints defined by the utility. The relationship between the reactive power compensation and the voltage is usually defined by a piecewise linear curve, as shown in Figure 3. 


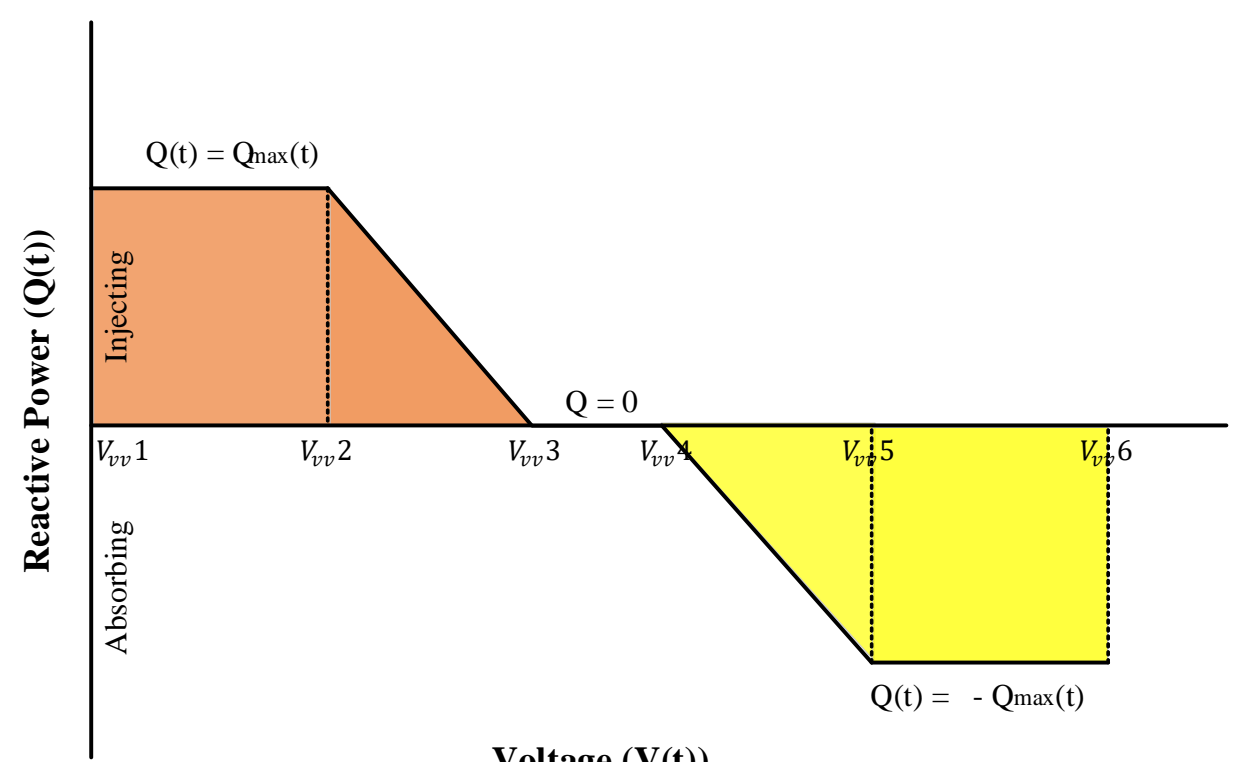

Voltage $(\mathbf{V}(t))$

Figure 3. Volt-Var curve characteristics.

As depicted in the figure, the maximum possible reactive power is injected between the $V_{v v} 1$ and $V_{v v} 2$ voltage range, while the reactive power injection in the range of $V_{v v} 2$ to $V_{v v} 3$ is based on the slope of the curve. Similarly, the reactive power absorption between the $V_{v v} 4$ and $V_{v v} 5$ voltage range is based on the slope of the curve, while the maximum possible reactive power is absorbed in the range of $V_{v v} 5$ to $V_{v v} 6$. The $V_{v v} 3$ to $V_{v v} 4$ voltage range covers the dead band region where no reactive power is injected or absorbed. The reactive power injection could be mathematically expressed as Equation (3).

$$
Q(t)=\left\{\begin{array}{cl}
Q_{\max }(t) & ; \text { if } V(t) \leq V_{v v} 2 \\
\frac{V_{v v} 3-V(t)}{V_{v v} 3-V_{v v} 2} Q_{\max }(t) & ; \text { if } V_{v v} 2<V(t) \leq V_{v v} 3 \\
0 & ; \text { if } V_{v v} 3<V(t) \leq V_{v v} 4 \\
-\frac{V_{v v} 4-V(t)}{V_{v v} 4-V_{v v} 5} Q_{\max }(t) & ; \text { if } V_{v v} 4<V(t) \leq V_{v v} 5 \\
-Q_{\max }(t) & ; \text { if } V(t)>V_{v v} 5
\end{array}\right.
$$

where $V(t)$ is the terminal voltage and $Q(t)$ is the computed reactive power injection by the Volt-Var control.

\subsection{Methodology}

Firstly, the topological and electrical data of the selected MV distribution network were used to develop a detailed network model connected with solar PV systems, and an impact analysis was performed to investigate the potential voltage issues associated with high PV integration into the network. In order to conduct a realistic analysis, different load profiles and irradiance profiles were employed to incorporate time variations in PV generation and load demand. Following that, the studied inverter controllers were implemented and adopted to alleviate the voltage problems in the network. Finally, a comparative analysis was performed using a variety of performance metrics, as described below.

- Number of nodes with voltage infringements: The daily voltage profiles of all nodes after the implementation of inverter controllers were evaluated for conformity with the local voltage limits, and the number of nodes that do not meet with permissible limits was obtained. According to the statutory limits specified by the Malaysian electric utility, Tenaga Nasional Berhad (TNB) for voltages in MV networks, the maximum and minimum voltage levels are 1.05 and 0.95 p.u., respectively. 
- Total daily average APC: The total daily average difference between the uncontrolled active power output at a unity power factor and the active power output of inverters with respective inverter controllers was computed.

- Total daily average RPA: The daily average reactive power absorption with respective inverter controllers was computed.

- Total daily average network loss: The daily average network loss of the entire system with respective inverter controllers was computed.

\section{Case Study}

\subsection{Test Network}

The test network is a generic Malaysian MV distribution network with two radial feeders serving a variety of residential, commercial, and industrial loads. The single-line diagram of the network is shown in Figure 4. The distribution feeders are connected to a 30 MVA distribution transformer with nominal voltage ratings of $33 / 11 \mathrm{kV}$. Feeders 1 and 2 of the network, as shown in the diagram, have 15 and 14 nodes, respectively. It was assumed that the maximum load demand of the network was $6 \mathrm{MW}$.

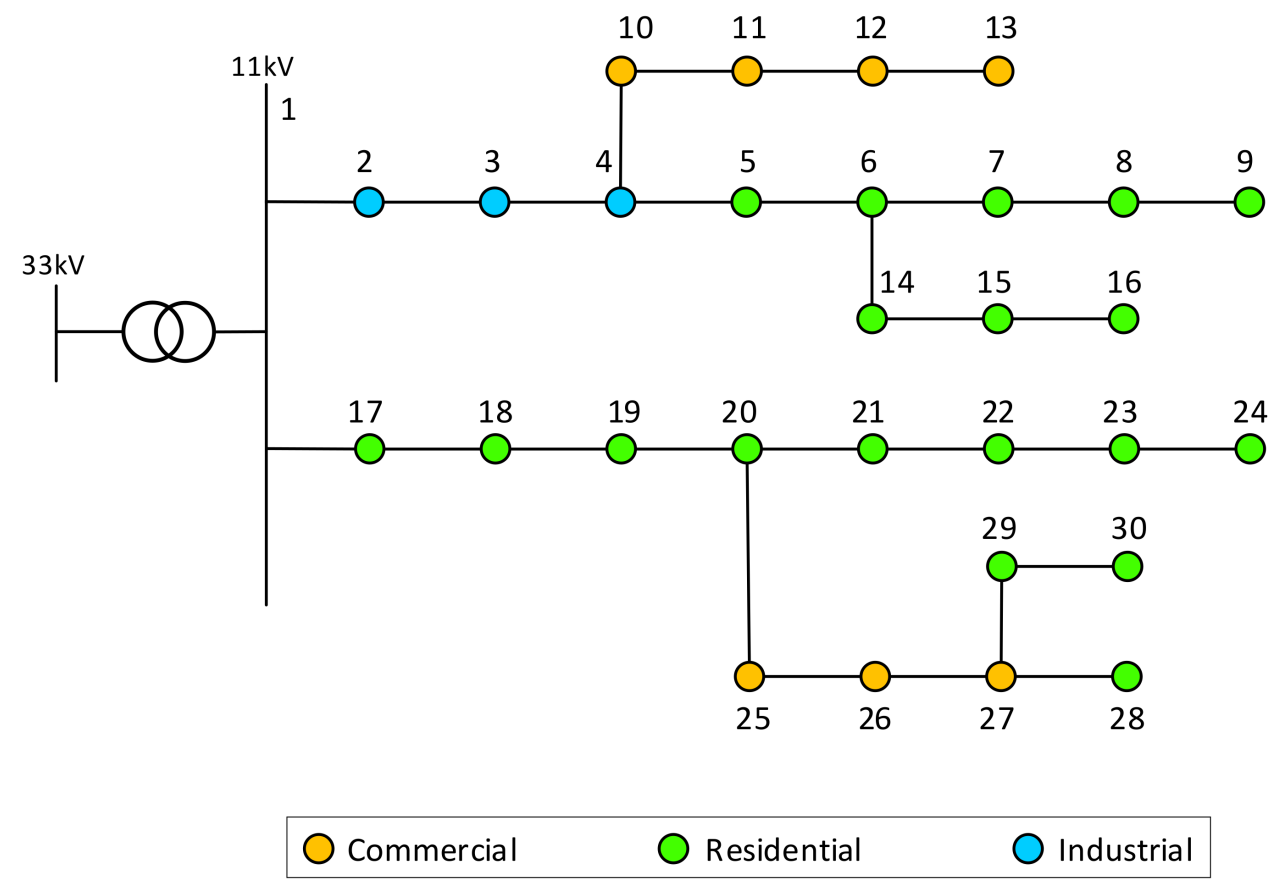

Figure 4. Single line diagram of the test network.

The basic network parameters of the test system are summarized in Table 1.

Table 1. Basic network parameters of the test network.

\begin{tabular}{|c|c|c|}
\hline \multicolumn{2}{|c|}{ Parameter } & Value \\
\hline \multicolumn{2}{|c|}{ Capacity } & 30 MVA \\
\hline \multicolumn{2}{|c|}{ Voltage } & $33 / 11 \mathrm{kV}$ \\
\hline \multicolumn{2}{|c|}{ Number of feeders } & 2 \\
\hline \multicolumn{2}{|c|}{ Number of nodes } & 30 \\
\hline \multirow{2}{*}{ Load connected } & Feeder 1 & $3.47 \mathrm{MW}$ \\
\hline & Feeder 2 & $2.53 \mathrm{MW}$ \\
\hline
\end{tabular}


The network parameters related to impedances and line segment lengths were based on the topological and electrical properties of typical Malaysian MV distribution networks (Appendix A). Figure 5 depicts the normalized PV generation and load consumption profiles, which were obtained by considering the maximum as 1 p.u. As illustrated in the figure, the residential customers usually have low consumption during the daytime, when solar PV generation is at its peak. The industrial customers, on the other hand, have high daytime consumption and lower nighttime consumption. In contrast, commercial customers have stable consumption during the daytime. In order to ensure overvoltage issues during high irradiance periods, a PV generation profile based on a sunny climatic condition was adopted.

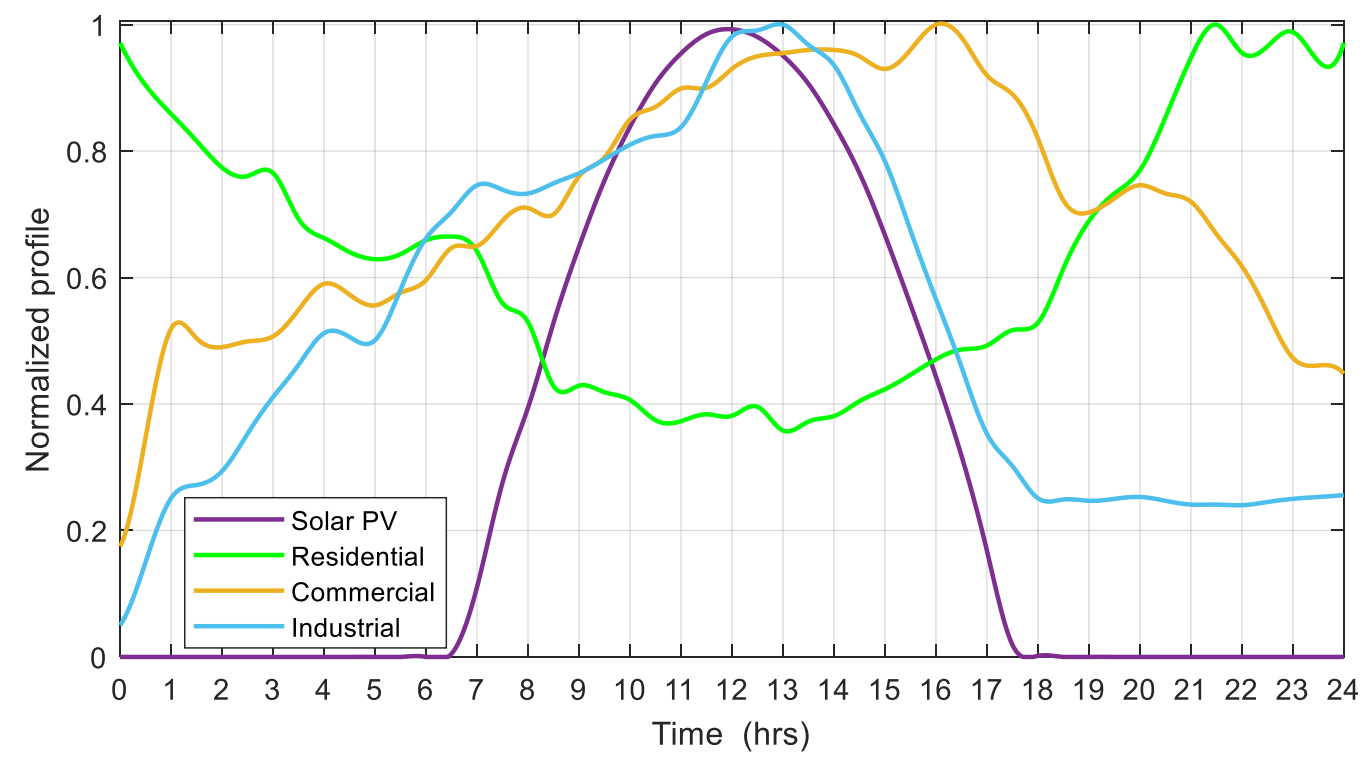

Figure 5. Normalized photovoltaic (PV) generation and load consumption profiles.

The test network model was developed in the Open Distribution System Simulator (OpenDSS) simulation platform interfaced with MATLAB software. A total PV generation of $24 \mathrm{MW}$ was installed by connecting an $800 \mathrm{~kW}$-rated PV plant with advanced PV inverter functionalities to each node of the network. A $10 \%$ oversized PV inverter was utilized to provide the reactive power support even when delivering the maximum active power generation, and all the PV plants were expected to experience the same irradiance profile.

Figure 6 illustrates the simplified block diagram of the OpenDSS PV system model with inverter controls. As indicated in the figure, the inverter could be controlled in two ways to alleviate overvoltage issues: static operation, in which the amount of reactive power absorbed from the network is weighted by a fixed power factor, and the inverter control operation (Volt-Watt and Volt-Var controls), in which the active and reactive power outputs are controlled via the smart inverter control (InvControl object), allowing changes to the inverter's operational settings. The InvControl object requires the operator to provide a control curve specified by an XY set of coordinates, as shown in Figures 1 and 3 . The most appropriate parameter settings were assigned in this study to achieve the best performance of the controller operation while successfully eliminating all voltage problems. 
Inverter Functions : VW and VV

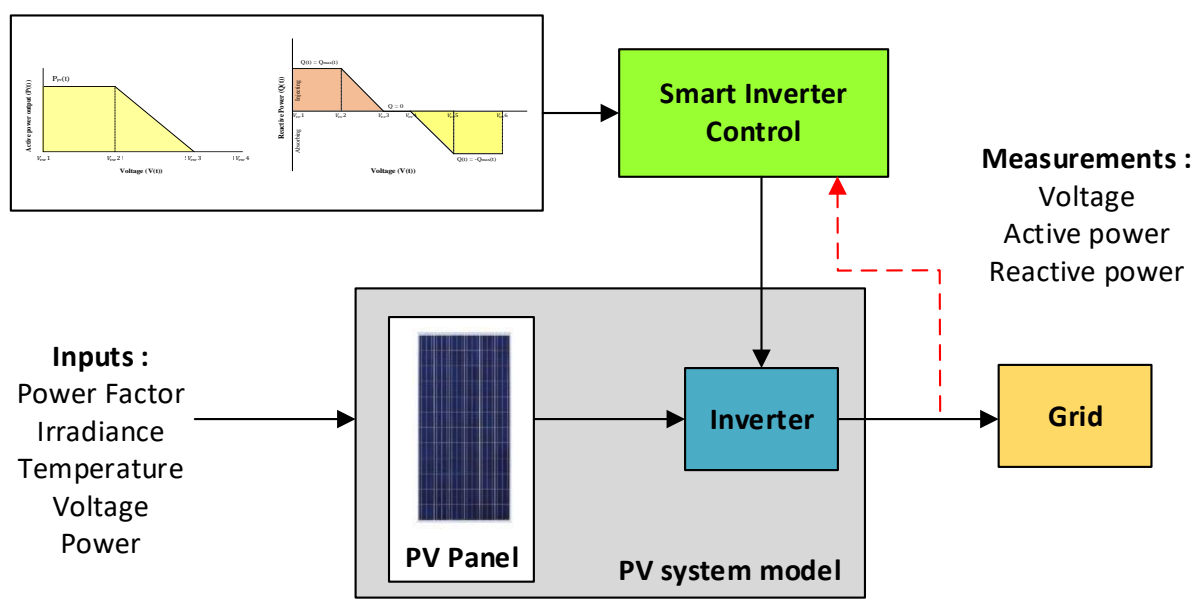

Figure 6. Block diagram of the OpenDSS PV system model with inverter controls.

\subsection{Controller Parameter Settings}

The adopted controller parameter settings for local active and reactive power control techniques of solar PV inverters are as follows.

- $\quad$ Base Case: The power factor of all solar PV inverters connected to the network was set to unity (the reactive power in-feed from the PV was 0).

- Volt-Watt control: The voltage setpoints were adjusted to commence the active power curtailment at 1.048 p.u. and to completely curtail the generation when the voltage reached the Malaysian upper voltage statutory limit for the MV distribution networks (1.05 p.u.).

- $\quad$ Fixed power factor control: The power factor of all solar PV inverters connected to the network was fixed at 0.98 (leading).

- Volt-Var control: The $V_{v v} 2$ and $V_{v v} 5$ setpoints (Figure 3) were adjusted to the lower and upper Malaysian statutory voltage limits for the MV distribution networks (0.95 and 1.05 p.u.). The $V_{v v} 3$ and $V_{v v} 4$ voltage setpoints were adjusted to enable the inverter to inject reactive power until the voltage reached 0.955 p.u. and to start to absorb reactive power when the voltage reached 1.045 p.u.

\section{Results}

Initially, power flow simulations were conducted for the base case scenario, in which all solar PV inverters connected to the network inject the maximum active power while absorbing no reactive power from the grid (unity power factor). The simulations were performed over a $24 \mathrm{~h}$ period using varying loads and PV profiles, as shown in Figure 5. The daily variation of nodal voltages reflecting every one-minute interval of the simulation time is presented in Figure 7. As anticipated, a voltage rise was observed during the peak generation, with 7 nodes identified with upper voltage statutory limit violations.

Thereafter, the studied APC and RPA techniques of solar PV inverters, that is, the fixed power factor, Volt-Var, and Volt-Watt controls, were implemented, as discussed in Section 3. After that, power flow simulations were conducted, utilizing the selected controller parameter settings to mitigate overvoltage infringements. The voltage profiles, active power generation, reactive power absorption, and network losses were extracted from every power flow simulation to assess the performance of the studied controllers. 


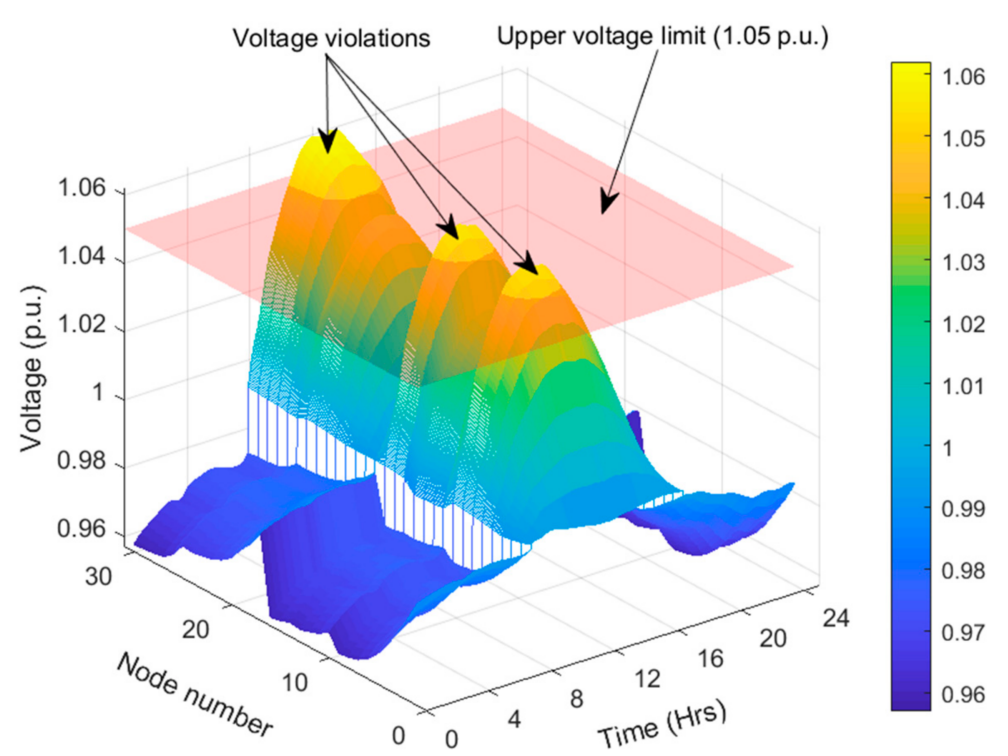

Figure 7. Daily variation of nodal voltages without voltage control.

Figures 8-10 depict the daily variation of the nodal voltages, active power generation, and reactive power absorption with the above controllers, respectively.

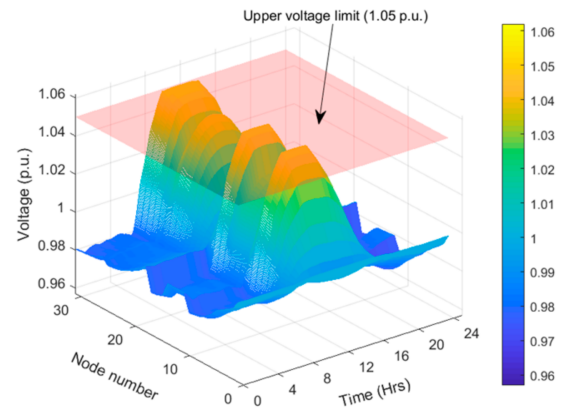

(a)

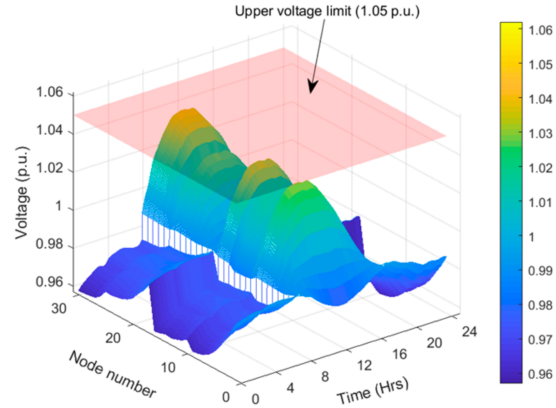

(b)

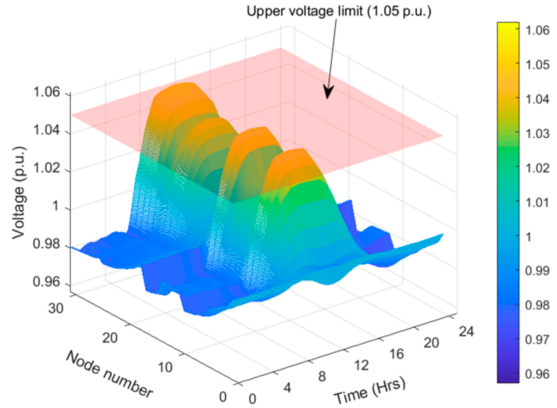

(c)

Figure 8. Daily variation of nodal voltages with the (a) Volt-Watt, (b) Fixed power factor, and (c) Volt-Var controls.

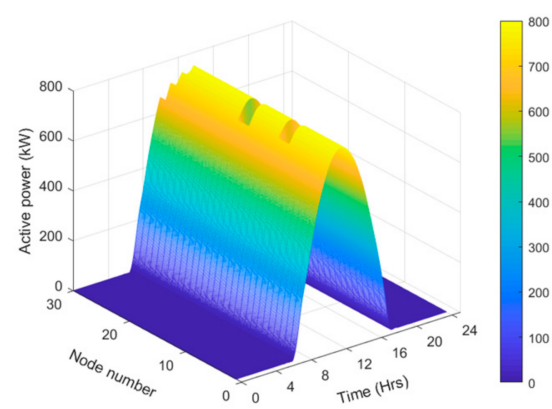

(a)

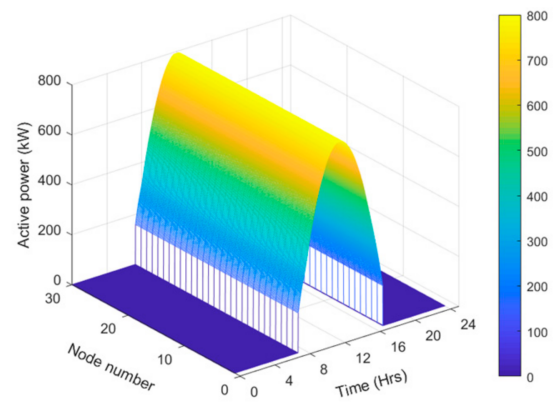

(b)

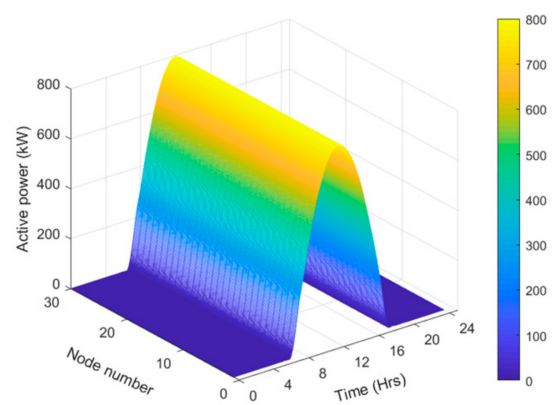

(c)

Figure 9. Daily active power generation with the (a) Volt-Watt, (b) Fixed power factor, and (c) Volt-Var controls. 


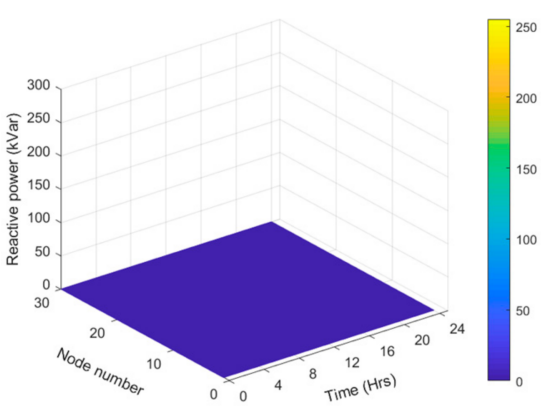

(a)

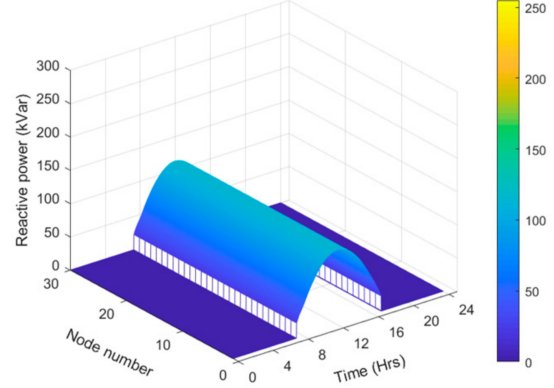

(b)

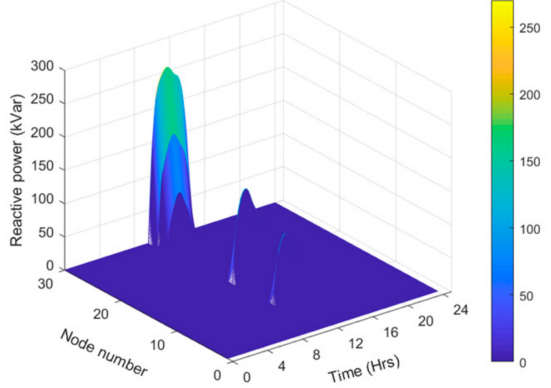

(c)

Figure 10. Daily reactive power absorption with the (a) Volt-Watt, (b) Fixed power factor, and (c) Volt-Var controls.

\section{Discussion}

As illustrated in Figure 8, the upper voltage limit violations observed in Figure 6 were successfully alleviated after the adoption of the studied APC and RPA techniques of solar PV inverters. According to the simulation results, the two RPA techniques were capable of preventing overvoltage problems while providing the maximum active power generation. In fact, due to the sufficient reactive power capability, the employment of overrated inverters has allowed for a complete active power generation, as shown in Figure 9. However, a substantial active power reduction was noted with the Volt-Watt control due to the curtailment of the active power output of solar PV inverters. The minimum daily active power generation for the Volt-Watt control was reported as 334.002 $\mathrm{kW}$, which is a $58.24 \%$ reduction from the maximum PV generation of $800 \mathrm{~kW}$.

As depicted in Figure 10, a significant RPA was observed with the fixed power factor control compared to the Volt-Var control. Moreover, it was reflected that all PV plants connected to the network have experienced an equal RPA with the fixed power factor control, while only the PV plants with higher voltages have substantially been involved in RPA with the Volt-Var control. Furthermore, it was revealed that the RPA of PV inverters connected closer to the distribution transformer with the Volt-Var control was negligible, owing to the low terminal voltages. According to the simulation results, the maximum RPA of $255.517 \mathrm{kVar}$ was reported with the Volt-Var control.

Table 2 and Figure 11 witness and depict the computed results for the comparative analysis of the studied APC and RPA techniques of solar PV inverters.

Table 2. Simulation results.

\begin{tabular}{ccccc}
\hline \multirow{2}{*}{ Parameter } & Base Case & \multicolumn{3}{c}{ Advanced Inverter Functionality } \\
\cline { 3 - 5 } & & $\begin{array}{c}\text { Volt-Watt } \\
\text { Control }\end{array}$ & $\begin{array}{c}\text { Fixed Power } \\
\text { Factor Control }\end{array}$ & $\begin{array}{c}\text { Volt-Var } \\
\text { Control }\end{array}$ \\
\hline $\begin{array}{c}\text { Number of nodes with voltage } \\
\text { infringements }\end{array}$ & 7 & 0 & 0 & 0 \\
$\begin{array}{c}\text { Total daily average APC (kW) } \\
\text { Total daily average RPC (kVar) }\end{array}$ & - & 108.238 & - & - \\
Total daily average network loss (kW) & 242.857 & 228.234 & 264.971 & 244.319 \\
\hline
\end{tabular}

As presented in the table, the adoption of the Volt-Watt control has contributed to an overall average active power reduction of $108.238 \mathrm{~kW}$. Moreover, the highest daily average RPA of $975.244 \mathrm{kVar}$ was reported with the fixed power factor control due to the unnecessary reactive power compensation regardless of the active power generation. It was evident that the main drawback of the fixed power factor control is the allocation of location-free reactive power references, regardless of the local voltage. In fact, it could unnecessarily absorb reactive power at periods when peak PV generation falls in with high load demand where voltage violations might not occur. A considerable increase in 
network loss could be seen in both RPA techniques compared to the base case scenario. The highest daily average network loss was reported with the fixed power factor control due to the extensive RPA, even in circumstances where the voltage was not in danger of being violated. This is a $9.11 \%$ increment over the operation of PV inverters with a unity power factor.
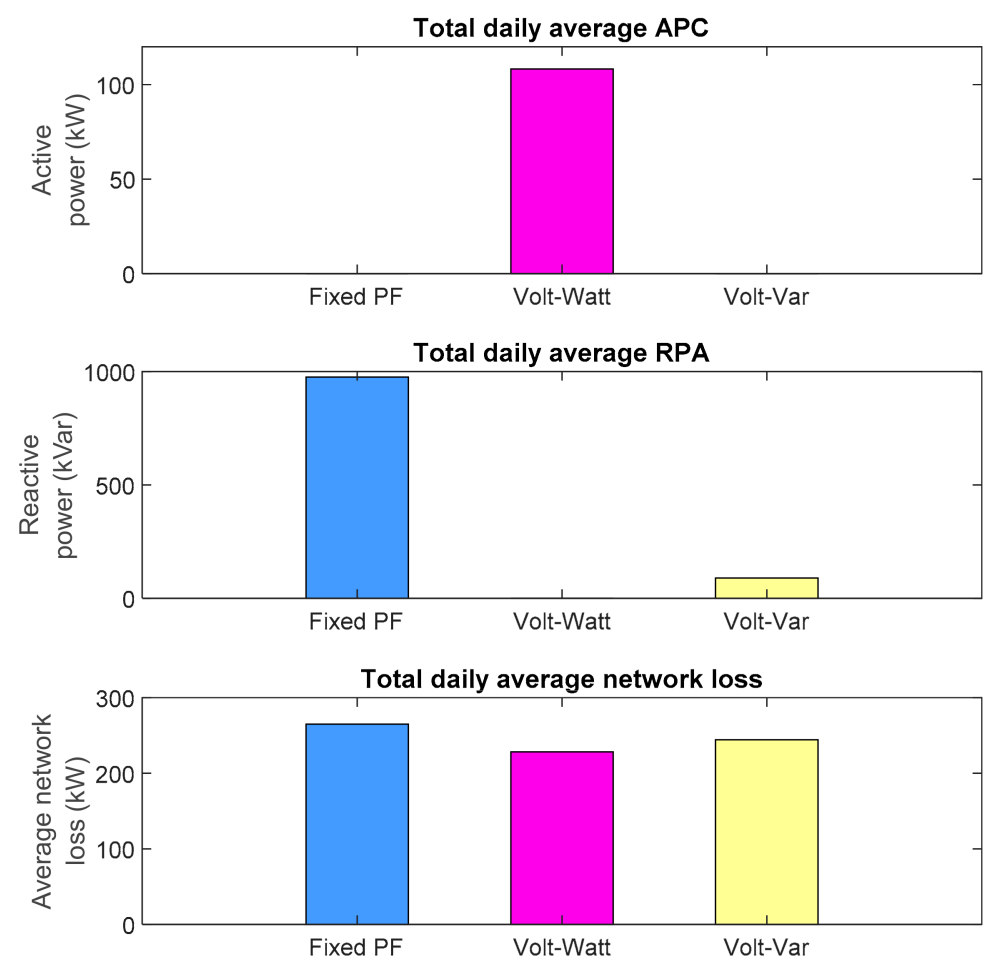

Figure 11. Comparison of simulation results.

According to the simulation results, the Volt-Var and Volt-Watt controls could be identified as the most prominent functionalities of modern solar PV inverters due to the autonomous control of active and reactive power output PV inverters based on the PCC voltage. Despite the fact that these functionalities are effective in resolving overvoltage issues, they possess inherent drawbacks that must be considered for implementation. The Volt-Var control depends on the reactive power capability of the PV inverter, where oversized inverters are recommended to provide reactive power support even when providing the maximum active power generation during peak irradiance periods. Due to the limitation of active power injected into the grid, the Volt-Watt control results in a revenue loss for prosumers/PV plant owners. Therefore, the Volt-Watt control could be implemented in circumstances where the reactive power support provided by the Volt-Var control is insufficient in alleviating all voltage violations in the network.

Beyond overvoltage mitigation, modern solar PV inverters are capable of frequencywatt control for over-frequency events, which necessitates active power curtailment to reduce excess generation. As per the revised IEEE Standard 1547, all DERs are required to be capable of frequency-watt control for both over-frequency and under-frequency events. Thus, PV systems are required to respond by increasing the power output of the inverter during an under-frequency event in order to avoid excessive load shedding, even if it is performing active power curtailment [26].

\section{Conclusions}

In this paper, several real and reactive power control techniques of solar PV inverters, namely the fixed power factor, Volt-Var, and Volt-Watt controls, were presented and evaluated to alleviate overvoltage issues due to high PV influx in MV distribution networks. 
The effectiveness of these controllers was examined and quantified on a generic Malaysian MV network, concerning a range of performance metrics, including the number of nodes with voltage infringements, active power curtailment, reactive power absorption, and network losses. The findings revealed that the studied APC and RPA techniques are capable of successfully surmounting the overvoltage problems in MV networks. Nonetheless, every controller comprises inherent drawbacks that must be considered by DNOs for implementation. Therefore, it is important to select appropriate remedial schemes based on the network configuration and level of PV penetration in order to provide efficient voltage control with minimal impact on prosumers and DNOs.

Author Contributions: Conceptualization, D.A.; methodology, D.A.; software, D.A.; writingoriginal draft preparation, D.A., J.P., S.K.R. and M.R.B.K.; writing—review and editing, D.A., J.P., S.K.R. and M.R.B.K.; visualization, D.A.; supervision, J.P. and S.K.R.; project administration, J.P.; funding acquisition, J.P. All authors have read and agreed to the published version of the manuscript.

Funding: This research was funded by Universiti Tenaga Nasional (UNITEN), Malaysia, under the BOLD Research Grant (RJO10517844/071), and the APC was funded by iRMC of UNITEN through J510050002-BOLDREFRESH2025-CENTRE OF EXCELLENCE.

Acknowledgments: The authors would like to thank Universiti Tenaga Nasional (UNITEN) Malaysia.

Conflicts of Interest: The authors declare no conflict of interest.

$\begin{array}{ll}\text { Abbreviations } \\ \text { PV } & \text { Photovoltaic } \\ \text { MV } & \text { Medium Voltage } \\ \text { DERs } & \text { Distributed Energy Resources } \\ \text { DNOs } & \text { Distribution Network Operators } \\ \text { APC } & \text { Active Power Curtailment } \\ \text { RPA } & \text { Reactive Power Absorption } \\ \text { PCC } & \text { Point of Common Coupling } \\ P(t) & \text { Computed active power output by Volt-Watt control } \\ V(t) & \text { Terminal voltage } \\ V_{v w} 1 & \text { Voltage setpoint } 1 \text { of Volt-Watt control } \\ V_{v w} 2 & \text { Voltage setpoint } 2 \text { of Volt-Watt control } \\ V_{v w} 3 & \text { Voltage setpoint } 3 \text { of Volt-Watt control } \\ V_{v w} 4 & \text { Voltage setpoint } 4 \text { of Volt-Watt control } \\ S_{i n v} & \text { Apparent power rating of the PV inverter } \\ P_{p v} & \text { Active power output of the PV inverter } \\ Q_{m a x}, & \text { Reactive power capability of the PV inverter } \\ Q_{l i m} & \text { Maximum possible reactive power of the PV inverter } \\ P_{\max } & \text { Maximum active power generation of the PV inverter } \\ Q(t) & \text { Computed reactive power injection by Volt-Var control } \\ V_{v v} 1 & \text { Voltage setpoint } 1 \text { of Volt-Var control } \\ V_{v v} 2 & \text { Voltage setpoint } 2 \text { of Volt-Var control } \\ V_{v v} 3 & \text { Voltage setpoint } 3 \text { of Volt-Var control } \\ V_{v v} 4 & \text { Voltage setpoint } 4 \text { of Volt-Var control } \\ V_{v v} 5 & \text { Voltage setpoint } 5 \text { of Volt-Var control } \\ V_{v v} 6 & \text { Voltage setpoint } 6 \text { of Volt-Var control } \\ & \\ \end{array}$




\section{Appendix A}

Table A1. Test network line impedance.

\begin{tabular}{|c|c|c|c|}
\hline \multicolumn{2}{|c|}{ Line Segment } & \multirow{2}{*}{ Length (km) } & \multirow{2}{*}{ Impedance $(\Omega / \mathrm{km})$} \\
\hline From Bus & To Bus & & \\
\hline 1 & 2 & 1.7 & \multirow{3}{*}{$0.08+j 0.0949$} \\
\hline 2 & 3 & 1.6 & \\
\hline 3 & 4 & 1.9 & \\
\hline 4 & 5 & 1.7 & \multirow{12}{*}{0.1609 + j0.1524 } \\
\hline 5 & 6 & 1.5 & \\
\hline 6 & 7 & 2.4 & \\
\hline 7 & 8 & 1.9 & \\
\hline 8 & 9 & 2.7 & \\
\hline 4 & 10 & 2.5 & \\
\hline 10 & 11 & 1.3 & \\
\hline 11 & 12 & 1.0 & \\
\hline 12 & 13 & 1.7 & \\
\hline 6 & 14 & 2.3 & \\
\hline 14 & 15 & 2.6 & \\
\hline 15 & 16 & 2.5 & \\
\hline 1 & 17 & 1.5 & \multirow{4}{*}{$0.08+j 0.0949$} \\
\hline 17 & 18 & 2.0 & \\
\hline 18 & 19 & 1.5 & \\
\hline 19 & 20 & 2.0 & \\
\hline 20 & 21 & 2.0 & \multirow{10}{*}{$0.1609+\mathrm{j} 0.1524$} \\
\hline 21 & 22 & 2.0 & \\
\hline 22 & 23 & 1.5 & \\
\hline 23 & 24 & 2.5 & \\
\hline 20 & 25 & 2.0 & \\
\hline 25 & 26 & 2.5 & \\
\hline 26 & 27 & 2.0 & \\
\hline 27 & 28 & 2.0 & \\
\hline 27 & 29 & 2.0 & \\
\hline 29 & 30 & 2.0 & \\
\hline
\end{tabular}

\section{References}

1. Karimi, M.; Mokhlis, H.; Naidu, K.; Uddin, S.; Bakar, A.H.A. Photovoltaic penetration issues and impacts in distribution network-A review. Renew. Sustain. Energy Rev. 2016, 53, 594-605. [CrossRef]

2. Alboaouh, K.A.; Mohagheghi, S. Impact of rooftop photovoltaics on the distribution system. J. Renew. Energy 2020, 2020, 1-23. [CrossRef]

3. Almeida, D.; Abeysinghe, S.; Ekanayake, M.P.; Godaliyadda, R.I.; Ekanayake, J.; Pasupuleti, J. Generalized approach to assess and characterise the impact of solar PV on LV networks. Int. J. Electr. Power Energy Syst. 2020, 121, 106058. [CrossRef]

4. Aziz, T.; Ketjoy, N. PV penetration limits in low voltage networks and voltage variations. IEEE Access 2017, 5, 16784-16792. [CrossRef]

5. Yan, R.; Saha, T.K. Investigation of voltage stability for residential customers due to high photovoltaic penetrations. IEEE Trans. Power Syst. 2012, 27, 651-662. [CrossRef]

6. Zhao, J.; Wang, C.; Zhao, B.; Lin, F.; Zhou, Q.; Wang, Y. A review of active management for distribution networks: Current status and future development trends. Electr. Power Compon. Syst. 2014, 42, 280-293. [CrossRef]

7. National Renewable Energy Laboratory. Advanced Inverter Functions to Support High Levels of Distributed Solar: Policy and Regulatory Considerations; National Renewable Energy Laboratory: Golden, CO, USA, 2014.

8. Xavier, L.S.; Cupertino, A.F.; Pereira, H.A. Ancillary services provided by photovoltaic inverters: Single and three phase control strategies. Comput. Electr. Eng. 2018, 70, 102-121. [CrossRef]

9. Pierno, A.; Di Noia, L.P.; Rubino, L. Ancillary services provided by PV power plants. Leonardo Electron. J. Pract. Technol. 2016, 15, 57-76.

10. Almeida, D.; Pasupuleti, J.; Ekanayake, J. Assessing the performance of smart inverter functionalities in PV-Rich LV distribution networks. In Proceedings of the 2020 IEEE Student Conference on Research and Development (SCOReD), Batu Pahat, Johor, Malaysia, 27-29 September 2020; pp. 90-95. [CrossRef] 
11. Lemkens, K.; Geth, F.; Vingerhoets, P.; Deconinck, G. Reducing overvoltage problems with active power curtailment-Simulation results. In Proceedings of the 2013 4th IEEE/PES Innovative Smart Grid Technologies Europe, ISGT Europe 2013, Lyngby, Denmark, 6-9 October 2013; pp. 1-5.

12. Tonkoski, R.; Lopes, L.A.C.; EL-Fouly, T.H.M. Droop-based active power curtailment for overvoltage prevention in grid connected PV inverters. IEEE Int. Symp. Ind. Electron. 2010, 2388-2393. [CrossRef]

13. Alyami, S.; Wang, Y.; Wang, C.; Zhao, J.; Zhao, B. Adaptive real power capping method for fair overvoltage regulation of distribution networks with high penetration of PV systems. IEEE Trans. Smart Grid 2014, 5, 2729-2738. [CrossRef]

14. Gómez-González, J.F.; Cañadillas-Ramallo, D.; González-Díaz, B.; Méndez-Pérez, J.A.; Rodríguez, J.; Sánchez, J.; Guerrero-Lemus, R. Reactive power management in photovoltaic installations connected to low-voltage grids to avoid active power curtailment. Renew. Energy Power Qual. J. 2018, 1, 5-11. [CrossRef]

15. Almeida, D.; Pasupuleti, J.; Ekanayake, J.; Karunarathne, E. Mitigation of overvoltage due to high penetration of solar photovoltaics using smart inverters volt/var control. Indones. J. Electr. Eng. Comput. Sci. 2020, 19, 1259-1266. [CrossRef]

16. Smith, J.W.; Sunderman, W.; Dugan, R.; Seal, B. Smart inverter volt/var control functions for high penetration of PV on distribution systems. In Proceedings of the 2011 IEEE/PES Power Systems Conference and Exposition, PSCE 2011, Phoenix, AZ, USA, 20-23 March 2011; pp. 1-6.

17. Demirok, E.; González, P.C.; Frederiksen, K.H.B.; Sera, D.; Rodriguez, P.; Teodorescu, R. Local reactive power control methods for overvoltage prevention of distributed solar inverters in low-voltage grids. IEEE J. Photovolt. 2011, 1, 174-182. [CrossRef]

18. Reno, M.J.; Broderick, R.J.; Grijalva, S. Smart inverter capabilities for mitigating over-voltage on distribution systems with high penetrations of PV. In Proceedings of the IEEE Photovoltaic Specialists Conference, Tampa, FL, USA, 20-25 June 2013; pp. 3153-3158.

19. IEEE Standard Association. IEEE Std. 1547-2018. Standard for Interconnection and Interoperability of Distributed Energy Resources with Associated Electric Power Systems Interfaces; IEEE: Piscataway, NJ, USA, 2018.

20. California Public Utilities Commission. Rule 21 Generating Facility Interconnections; California Public Utilities Commission: San Francisco, CA, USA, 2014.

21. Hawaii Public Utility Commission. Revised Rule 14H; Hawaii Public Utility Commission: Honolulu, HI, USA, 2018.

22. Farkas, C.; Tóth, A.; Orlay, I. Voltage control methods in the MV grid with a large share of PV. Int. J. Emerg. Electr. Power Syst. 2019, 20,1-12. [CrossRef]

23. Adiguno, F.K.; Mai, T.T.; Nguyen, P.H. Mitigation impact of large-scale PV integration on MV distribution network with sequential control functions: A case of study in Noordwolde grid, the Netherlands. In Proceedings of the 25th International Conference and Exhibition on Electricity Distribution, Madrid, Spain, 3-6 June 2019; pp. 1-5. [CrossRef]

24. Shi, Q.; Feng, W.; Zhang, Q.; Wang, X.; Li, F. Overvoltage mitigation through Volt-VAR control of distributed PV systems. In Proceedings of the 2020 IEEE/PES Transmission and Distribution Conference and Exposition, Chicago, IL, USA, 12-15 October 2020; pp. 1-5. [CrossRef]

25. Kryonidis, G.C.; Demoulias, C.S.; Papagiannis, G.K. A probabilistic evaluation of voltage control strategies in active MV networks. In Proceedings of the 2017 52nd International Universities Power Engineering Conference, Heraklion, Greece, 28-29 August 2017; pp. 1-6. [CrossRef]

26. Hoke, A. Fast Grid Frequency Support from Distributed Inverter-Based Resources; National Renewable Energy Laboratory: Golden, CO, USA, 2018. 